\title{
In Situ and Ex Situ Monitoring of Oxygen Absorption in $\mathrm{YBaCo}_{4} \mathrm{O}_{7+\delta}$
}

\author{
Markus Valkeapää, ${ }^{1,2}$ Maarit Karppinen, ${ }^{1,2}$ Teruki Motohashi, ${ }^{2}$ Ru-Shi Liu, ${ }^{3}$ Jin-Ming Chen, ${ }^{4}$ and Hisao Yamauchi ${ }^{2}$ \\ ${ }^{1}$ Helsinki University of Technology TKK, Laboratory of Inorganic and Analytical Chemistry, FI-02015 TKK, Finland \\ ${ }^{2}$ Materials and Structures Laboratory, Tokyo Institute of Technology, Yokohama 226-8503 \\ ${ }^{3}$ Department of Chemistry and Center for Nano Storage Research, National Taiwan University, Taipei 106, Taiwan \\ ${ }^{4}$ National Synchrotron Radiation Research Center (NSRRC), Hsinchu 300, Taiwan
}

(Received August 24, 2007; CL-070907; E-mail: markus.valkeapaa@tkk.fi)

Oxygen absorption in $\mathrm{YBaCo}_{4} \mathrm{O}_{7+\delta}$ was studied by in situ XRD and by XANES spectroscopy. Unit cell of $10.875 \times$ $10.168 \times 12.788 \AA^{3}$ (Pnna) was found for the oxygenated phase. XANES shows that oxygen absorption increases the number of different crystallographic sites for Co.

Recently, an uncommon oxygen absorption/desorption behavior was found for $\mathrm{YBaCo}_{4} \mathrm{O}_{7+\delta} .{ }^{1}$ The compound absorbs and desorbs oxygen up to $\delta \approx 1.5$ in a narrow temperature range below $400{ }^{\circ} \mathrm{C}$. Such a large oxygen-content tunability is of great promise in regards to applications related to, e.g., oxygen storage. Crystal structure of the parent $\mathrm{YBaCo}_{4} \mathrm{O}_{7}$ phase is known, ${ }^{2,3}$ but no unit cell for the oxygen-rich phase has been proposed. The aim of our in situ X-ray diffraction (XRD) study in $\mathrm{O}_{2}$ at elevated temperatures was to observe the formation of the oxygenated phase. For this purpose a sample of $\mathrm{YBaCo}_{4} \mathrm{O}_{7.0}$ was prepared by an EDTA complexation method. ${ }^{1}$ Since XANES (X-ray absorption near-edge structure) is sensitive to the local structure and thus compliments XRD which gives information on the average structure, we also performed ex situ XANES measurements on the $\mathrm{YBaCo}_{4} \mathrm{O}_{7.0}$ sample and on its oxygen-annealed $\left(350{ }^{\circ} \mathrm{C}, 5 \mathrm{~h}\right)$ form $\mathrm{YBaCo}_{4} \mathrm{O}_{8.2}$ at $\mathrm{Co} \mathrm{L}$ - and $\mathrm{O}$ K-edges. Oxygen contents were determined by thermogravimetry.

XRD data were collected with a diffractometer (Rigaku RINT-TTR II) equipped with a $\mathrm{Cu} \mathrm{K} \alpha$ rotating anode and a temperature- and atmosphere-controlled chamber (Rigaku SHT-1500). Experimental details of the XANES measurements performed at NSRRC in Taiwan were similar to those in ref 4. The O K-edge spectra recorded by X-ray fluorescence yield mode were corrected for self-absorption effects using the program Athena. ${ }^{5}$ The Co L-edge spectra were measured by collecting the sample drain current.

Along with temperature increase, the intake and subsequent release of oxygen ${ }^{1}$ is accompanied by structural changes, as demonstrated here by the evolution of diffraction patterns in Figure 1. As temperature increases, the changes take place at $300{ }^{\circ} \mathrm{C}$, most notably a shoulder at the right-hand side of 103 reflection, disappearance of 200 reflection, and an apparent shift of 004 reflection. At $350^{\circ} \mathrm{C}$ the diffraction pattern consists of broad Bragg reflections and clearly differs from the roomtemperature pattern. When the temperature is further increased, at $500{ }^{\circ} \mathrm{C}$ the diffraction pattern returns to the original, save for the differences due to thermal expansion. Before and after the heating-and-cooling cycle (i.e., the intake and release of oxygen) the diffraction patterns are essentially the same.

In addition to aforementioned changes in the XRD pattern, several small intensity peaks are observed in patterns collected

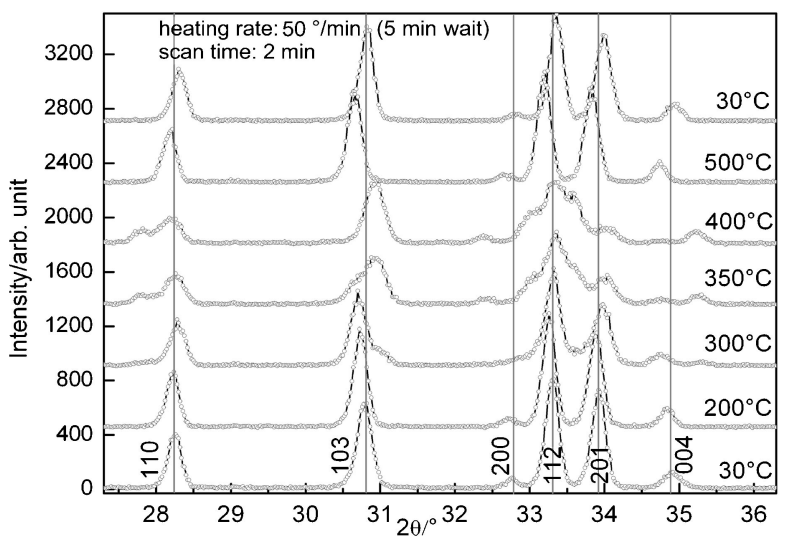

Figure 1. $\mathrm{YBaCo}_{4} \mathrm{O}_{7+\delta}$ diffraction patterns at different temperatures.

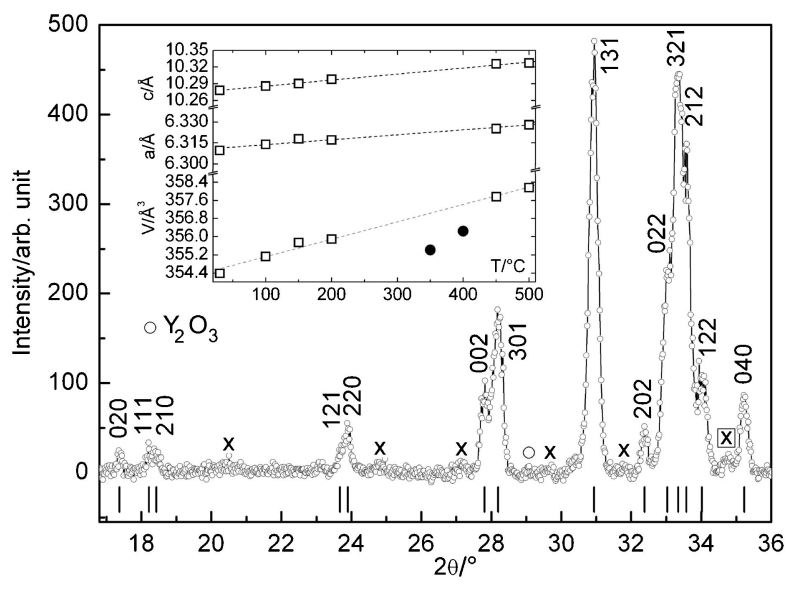

Figure 2. XRD pattern of the high- $\delta$ phase collected at $400{ }^{\circ} \mathrm{C}$. Insert: $a_{\mathrm{h}}$ vs. $T, c_{\mathrm{h}}$ vs. $T$, and unit volume vs. $T$. Open squares: parent phase, closed circles: oxygenated phase.

at $300-400{ }^{\circ} \mathrm{C}$. These are marked with " $\mathrm{x}$ " in Figure 2.

Owing to the partial overlap of the high- $\delta$ and parent-phase reflections it is not obvious whether the patterns at $300-400{ }^{\circ} \mathrm{C}$ originate from a single phase. The overlap, together with the small intensity peaks, leads to a situation where the pattern indexing $\left(\mathrm{DICVOL}^{6}\right)$ gives several suggestions for the unit cell of the high- $\delta$ phase. Two most likely solutions are reported here. Assuming that the oxygen intake is not complete, it is possible that some unreacted parent phase remains at $300-400{ }^{\circ} \mathrm{C}$. This is the situation shown in Figure 2: indexed reflections belong to an orthorhombic (o) unit cell $10.884 \times 10.190 \times$ 

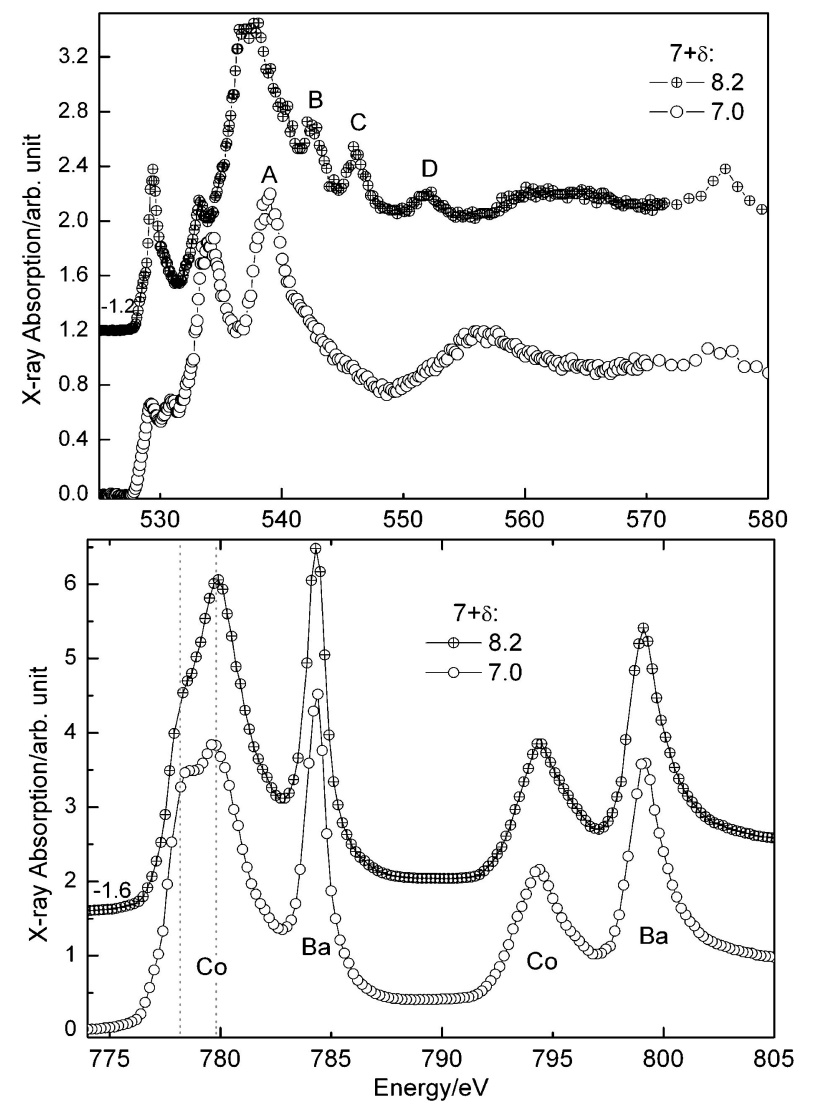

Figure 3. Co L-, Ba M- (bottom), and O K-edge (top) XANES spectra of $\mathrm{YBaCo}_{4} \mathrm{O}_{7.0}$ and $\mathrm{YBaCo}_{4} \mathrm{O}_{8.2}$.

$6.412 \AA^{3}$ in space group Pnna (Cell 1). Note that the unit cell parameters resemble those of the hexagonal $(\mathrm{h})$ parent phase $\mathrm{YBaCo}_{4} \mathrm{O}_{7.0}: a_{\mathrm{o}} \approx \sqrt{ } 3 a_{\mathrm{h}}, b_{\mathrm{o}} \approx c_{\mathrm{h}}$, and $c_{\mathrm{o}} \approx a_{\mathrm{h}}\left(a_{\mathrm{h}}=6.309 \AA\right.$, $\left.c_{\mathrm{h}}=10.278 \AA\right)$. Most of the reflections from Cell 1 overlap partially with those from the parent phase. The small intensity peak at $2 \theta=34.7^{\circ}$ (rectangle enclosing " $x$ ") is an exception and could be 004 reflection of the parent phase, thus indicating that $\mathrm{YBaCo}_{4} \mathrm{O}_{7.0}$ is present. However, by including both sets of reflections, vertical tick marks and " $x$," indexing results in a unit cell with similar $a$ and $b$ but approximately doubled $c$ : $10.875 \times 10.168 \times 12.788 \AA^{3}$ (Cell 2). Two-phase LeBail profile fitting ${ }^{7,8}$ gives similar results for both possibilities: $R_{\mathrm{p}}=15.33 \%$ for $\mathrm{YBaCo}_{4} \mathrm{O}_{7.0}$ and Cell 1 , and $R_{\mathrm{p}}=15.85 \%$ for $\mathrm{YBaCo}_{4} \mathrm{O}_{7.0}$ and Cell 2. Although the latter (supercell) fitting yields a slightly larger $R$-factor, it accounts better for the observed reflections and is thus more likely to be the correct cell.

Insert in Figure 2 shows the variation of the hexagonal cell parameters $a$ and $c$ before and after the oxygen intake-and-release. The dashed line of a linear fit shows how, after the oxygen release, the unit cell size returns to the one which is expected for the given temperature. The slopes for $a$ vs. $T$ and $c$ vs. $T$ are different, which reveals that thermal expansion is anisotropic, being more pronounced along $c$. Also shown in the insert is the temperature dependence of the unit volume. It is seen that during oxygen intake the volume decreases. This is due to the oxidation of cobalt upon the oxygen intake. Relationship of Cells 1 and 2 to that of $\mathrm{YBaCo}_{4} \mathrm{O}_{7.0}$ is interesting: in both cases $a_{0}$ of the high- $\delta$ phase is approximately equal to $\sqrt{ } 3 a_{\mathrm{h}}$ of the $\mathrm{YBaCo}_{4} \mathrm{O}_{7.0}$ phase. Upon oxygenation the parent phase is being modified: $a_{\mathrm{h}} \times a_{\mathrm{h}} \times c_{\mathrm{h}} \rightarrow \approx \sqrt{3} a_{\mathrm{h}} \times \approx c_{\mathrm{h}} \times \approx 2 a_{\mathrm{h}}$.

Oxygen K-edge XANES spectra of $\mathrm{YBaCo}_{4} \mathrm{O}_{7.0}$ and $\mathrm{YBaCo}_{4} \mathrm{O}_{8.2}$ are shown in Figure 3 (top). The pre-edge onset position at $\approx 528 \mathrm{eV}$ is the same for both spectra, but the intensity of the pre-edge peak increases as the sample's oxygen content increases. Absorption feature at the pre-edge is related to $\mathrm{Co} 3 \mathrm{~d}-\mathrm{O} 2 \mathrm{p}$ hybridized orbitals, and its increased intensity indicates oxidation of cobalt (from $\mathrm{Co}^{\mathrm{II}}$ to $\mathrm{Co}^{\mathrm{III}}$ in this case). In addition to the intensity differences at the pre-edge, $\mathrm{O} \mathrm{K}$-edge spectrum of $\mathrm{YBaCo}_{4} \mathrm{O}_{8.2}$ has additional absorption peaks $(\mathrm{B}, \mathrm{C}$, and $\mathrm{D}$ ); indicating a mixture of $\mathrm{Co}-\mathrm{O}$ coordination geometries in the sample, ${ }^{9}$ i.e., the local structure of $\mathrm{Co}$ is more diversiform in $\mathrm{YBaCo}_{4} \mathrm{O}_{8.2}$ than in $\mathrm{YBaCo}_{4} \mathrm{O}_{7.0}$.

Figure 3 (bottom) shows XANES spectra in the energy range $775-805 \mathrm{eV}$ for the two samples. The spectra display absorption peaks from both Co L-edge and $\mathrm{Ba}$ M-edge. For the most part, the spectra overlap but there is a small positive shift in the spectral weight in the case of Co L-edge, whereas the $\mathrm{Ba} \mathrm{M}$-edge peak remains almost unchanged upon oxygenation. The shift towards higher energy in the Co L-edge peak indicates increasing oxidation state of cobalt and/or changes in the coordination sphere of Co atoms.

To summarize, we have followed the changes in the XRD patterns of $\mathrm{YBaCo}_{4} \mathrm{O}_{7+\delta}$ during oxygen intake and release. The unit cell of $10.875 \times 10.168 \times 12.788 \AA^{3}$ in space group Pnna was found for the high- $\delta$ phase. We have shown by XANES that the oxygen absorption increases the number of different crystallographic sites for $\mathrm{O}$ and $\mathrm{Co}$ atoms, i.e., the structure becomes more complicated in terms of $\mathrm{Co}-\mathrm{O}$ coordination.

The present work was supported by Academy of Finland (Dec. 110433). M. V. thanks Japan Society for the Promotion of Science for FY2004 postdoctoral fellowship.

\section{References}

1 M. Karppinen, H. Yamauchi, S. Otani, T. Fujita, T. Motohashi, Y. Huang, M. Valkeapää, H. Fjellvåg, Chem. Mater. 2006, 18, 490.

2 M. Valldor, M. Andersson, Solid State Sciences 2002, 4, 923.

3 A. Huq, J. F. Mitchell, H. Zheng, L. C. Chapon, P. G. Radaelli, K. S. Knight, P. W. Stephens, J. Solid State Chem. 2006, 179, 1136.

4 M. Valkeapää, Y. Katsumata, I. Asako, T. Motohashi, T. S. Chan, R. S. Liu, J. M. Chen, H. Yamauchi, M. Karppinen, J. Solid State Chem. 2007, 180, 1608.

5 B. Ravel, M. Newville, J. Synchrotron Rad. 2005, 12, 537.

6 A. Boultif, D. Louër, J. Appl. Cryst. 2004, 37, 724.

7 A. Le Bail, Abstracts of the Satellite Meeting on Powder Diffraction of the XV Congress of the IUCr, 1990, p. 99.

8 V. Petricek, M. Dusek, The Crystallographic Computing System JANA2000, Inst. of Phys., Praha, Czech Republic, 2000.

9 J. J. Rehr, R. C. Albers, Rev. Mod. Phys. 2000, 72, 621. 